\title{
RESEARCH
}

Open Access

\section{IDC theory: habit and the habit loop}

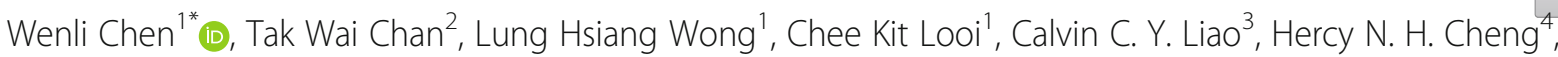
Su Luan Wong ${ }^{5}$, Jon Mason ${ }^{6}$, Hyo-Jeong So ${ }^{7}$, Sahana Murthy ${ }^{8}$, Xiaoqing $\mathrm{Gu}^{9}$ and Zhongling Pi ${ }^{1}$

\author{
* Correspondence: Wenli.chen@nie. \\ edu.sg \\ ${ }^{1}$ National Institute of Education, \\ Nanyang Technological University, \\ Singapore, Singapore \\ Full list of author information is \\ available at the end of the article
}

\begin{abstract}
Interest-driven creator (IDC) theory is a design theory that intends to inform the design of future education in Asia. It consists of three anchored concepts, namely, interest, creation, and habit. This paper presents the third anchored concept habit as well as the habit loop. IDC theory assumes that learners, when driven by interest, can be engaged in knowledge creation. Furthermore, by repeating such process in their daily learning routines, learners will form interest-driven creation habits. The habit loop, the process of building such a habit, consists of three component conceptscuing environment, routine, and harmony. The cuing environment is a habit trigger that tells the students' brain to get prepared and go into an automatic mode, letting a learning behavior unfold. Routine refers to the behavioral patterns the students repeat most often, literally etched into their neural pathways. Harmony refers to the affective outcome of the routine activity as well as the integration or stabilization of habits; that is, through the routine behavior and action, students may feel that their needs get fulfilled, feel satisfied, and experience inner peace. It is our hope that such habitual behavior of creating knowledge can be sustained so long that students ultimately become lifelong interest-driven creators. This paper focuses on the description of the three components of the habit loop and discusses how these components are related to the interest loop and the creation loop in supporting learners in developing their interest-driven creation capability.
\end{abstract}

Keywords: Interest-driven creator (IDC) theory, Learning habit, Habit loop

\section{Introduction}

Researchers, educators, and parents have long acknowledged the importance of cultivating students' good habits for learning. Learning involves a persistent and stable change in what a person knows or does. Learning habits exercise significant influences over students' learning and development. The influential Chinese author and educator Yeh Sheng-Tao stated "what is education? To answer it in a simple way, we just need one statement: nurturing good habits." Habit is a routine of behavior that is repeated regularly and tends to occur unconsciously. From the viewpoint of psychologists, habit is understood as "a more or less fixed way of thinking, willing, or feeling acquired through previous repetition of mental experience (Andrews 1903, p.1). As Ronis et al. (1989) mentioned, "habits are the result of automatic cognitive processes, developed by extensive repetition, so well learned that they do not require conscious effort (p. 219)".

(c) The Author(s). 2020 Open Access This article is licensed under a Creative Commons Attribution 4.0 International License, which permits use, sharing, adaptation, distribution and reproduction in any medium or format, as long as you give appropriate credit to the original author(s) and the source, provide a link to the Creative Commons licence, and indicate if changes were made. The images or other third party material in this article are included in the article's Creative Commons licence, unless indicated otherwise in a credit line to the material. If material is not included in the article's Creative Commons licence and your intended use is not permitted by statutory regulation or exceeds the permitted use, you will need to obtain permission directly from the copyright holder. To view a copy of this licence, visit http://creativecommons.org/licenses/by/4.0/. 
The online Oxford Dictionary (2014) defines habit as "a settled or regular tendency or practice, especially one that is hard to give up" and "an automatic reaction to a specific situation."

Currently, Asians are still examination-driven educational culture, governed by the short-term goal of obtaining high scores in examinations (Chan et al. 2018). Thus, forming good habits of learning, especially interest-driven learning, has not been sufficiently considered in formal schooling. However, when it comes to skill development, practice is understood as essential (Raisbeck et al. 2015). To face the fast-changing world, citizens must develop and adopt habits of lifelong learning and acquire skills such as complex problem solving, collaboration and communication, critical thinking and reflection, and creativity and imagination (Chan 2013; Griffin et al. 2012).

Given the previously mentioned educational challenge and expectation, a group of Asian researchers came together collaboratively to propose a macro-level theory called interest-driven creator (IDC) theory. The preliminary work giving an overview of IDC theory and highlighting its origin with some history was published in 2018 (Chan et al. 2018). According to IDC theory, when driven by interest, students can be engaged in the creation of knowledge (ideas and artifacts). By repeating this interest-driven creation process in their daily learning routines, students will develop twenty-first century skills, form a habit of creation, and excel in learning.

This paper is last in a three-part series of IDC theory which examines in detail the third anchored concept-habit. It focuses on how habits are built through interestdriven creation activities undertaken as daily learning routines. The two other papers focus on:

- Interest, which examined the first anchored concept of IDC emphasizing the significance of promoting student learning through interest;

- Creation, which examined the second anchored concept of IDC emphasizing student learning through creation activities and the design of interest-driven creations.

Interest and creation, as described in the two preceding papers, are not just concepts for educators to perceive and understand. IDC theory calls for actions by practicing in everyday routines. The ultimate goal of IDC theory is to nurture our next generation to become lifelong interest-driven creators. Only by forming a habit of interest-driven creation - a habit hopefully sustaining for life-can the ultimate goal be realized. If interest talks about why we learn and creation about how we learn, then habit talks about how often we learn in order to realize the learning goal. Given that creation is a complex cognitive process, building a habit of creation is a long-term undertaking.

\section{Habit}

Building up good habit is a fundamental issue for human life because our behavior is largely affected by our habits. To some degree, our habits define who we are. Many philosophers, psychologists, and educators have emphasized the importance of habit. The notion of habits of mind encapsulates many prior discussions (Costa and Kallick 2008). The pioneering psychologist and philosopher James (1890) states in his talks to teachers: "All our life, so far as it has definite form, is but a mass of habits." Greek 
philosopher and scientist Aristotle famously proclaimed: "We are what we repeatedly do." "Excellence, then, is not an act, but a habit." The same goes for the reverse: problems and failure can become habits too. Those who have formed good habits have higher chance to excel in various aspects of life.

According to Azikiwe (1998), "good study habits are good assets to learners because the (habits) assist students to attain mastery in areas of specialization and consequent excellent performance, while opposite constitute constraints to learning and achievement leading to failure." The learning habit greatly determines not only students' academic achievements but also their success in the future (Chan et al. 2018; Ebele and Olofu 2017).

Students' achievements due to good habit have a cumulative effect on their future success. Therefore, those students who have developed good learning habits earlier continue to sustain and increase the learning gains while those students who have not had good learning habits have a harder time catching up-essentially, the stronger gets ever stronger while the weaker only gets weaker, due to learning habits. This is consistent with the research findings that suggest that prior learning performance of an experience is a good predictor of future learning (Jonassen and Grabowski 1993). This exactly illustrates Nathaniel Emmons' saying that "habit is either the best of servants or the worst of masters".

Some researchers have attempted to cultivate students' good learning habits to make them as lifelong learners with the twenty-first century competencies, such as critical and creative thinking, self-regulated learning, problem solving, and collaborative learning skills. Such habits of mind (or habits of thought, as John Dewey originally referred to them) require little or no effort on the part of the child to initiate or sustain them and would include inclinations to take responsible risks, persistence, manage impulsivity, and think 'outside the box' in problem-solving situations (Whitebread and Bingham 2013). Costa and Kallick (2008) explain how habits of mind may be cultivated in children. They show how children can be taught, at home and at school, how to "habituate" effective problem-solving strategies and techniques into their mental repertoire, so that they develop the propensity for skillful problem-solving in a variety of real life settings. Good learning habits can be formed in student's schooling and be sustained lifelong.

Habit can be classified into three types. The first is motor habits which refer to the muscular activities of an individual (Rueda-Orozco and Robbe 2015). These are the habits related to our physical actions such as standing, sitting, running, walking, doing exercise, and maintaining particular postures of body. The second type is intellectual/ cognitive habits which are related to psychological process requiring our intellectual abilities such as good observation, accurate perception, logical thinking, use of reasoning ability before taking decisions and testing conclusions, and others (Hertel and Brozovich 2010). The third type is habits of character. Some of our characters are expressed in the form of habits (Peterson et al. 2017). For example, helping others, trusting people, time management, and being hardworking. These habits will have essence of feelings and emotions; hence, these are also called as emotional habits. In this paper, the term habit is widened from the oft-repeated action or an established practice or custom requiring little thought (such as brushing teeth or adding sugar to one's coffee) to mean unconscious mental propensities or processes, revealed as behavioral tendencies and dispositions as the student engages with the events and challenges of learning especially in the context of interest-driven creation. 
In educational and learning contexts, not only individual students develop the habit of learning but also groups develop habitual routines in response to recurring questions and become accepted practice-actions taken without consciously considering alternatives. A habitual routine or script exists when a group repeatedly exhibits a functionally similar pattern of behavior in a given stimulus situation without explicitly selecting it over alternative ways of behaving (Gersick and Hackman 1990, p.69). Likewise, IDC theory applies to both individuals and groups. Students often engage in group activities when they are creating knowledge or artifacts. The groups require at least some routinization of behavior to get work accomplished, while they are able to predict the responses of other individuals for coordinated action to be possible. Group routinization contributes to predictability.

\section{Formation of habit}

To cultivate good habits of students for interest-driven creation, we need to have a deep understanding of habit formation. Habit formation is the process by which new behaviors become automatic (Bargh 1994). A habit is a regularly repeated behavior pattern: a routine that is practiced frequently and hard to stop. Habit formation is the process by which new behaviors become automatic (Bargh 1994). While the link between habits and learning is widely recognized, there is much less research that investigates how learning habits are formed in various circumstances with different learners. An example of such research is Lally et al.'s (2010) study on how to promote habit formation. They explored on strategies to initiate a new behavior, support contextdependent repetition of this behavior (cuing environment), and facilitate the development of automaticity. Lally and her colleagues also provided the assumption that repeating a behavior in a consistent setting increases automaticity. Moreover, the term, habit, refers to a behavior that is done automatically with little thought.

As James (1890) put it, "Any sequence of mental action which has been frequently repeated tends to perpetuate itself; so that we find ourselves automatically prompted to think, feel, or do what we have been before accustomed to think, feel, or do, under like circumstances, without any consciously formed purpose, or anticipation of results" (p.439). This simply means that we tend to repeatedly do the same thing under similar circumstances. Durhigg (2012) added a term "reward" and considered that a habit can be thought of as being composed of three parts: a cue, a routine, and a reward. Adapting James' and subsequent Durhigg's framework, we proposed a habit formation framework to guide the design of a coherent learning process that encompasses a series of learning tasks. This habit loop consists of three components: cuing environment (arrangement of place, time, people, or incidents), routine (repetitive pattern of activities), and harmony (an outcome of activating the habit), forming the habit loop (Fig. 1). We will delineate the habit loop and discuss how such a "habit loop" can be integrated in the design of learning activities with the ultimate aim of nurturing lifelong learners.

\section{Cuing environment}

Environment is the invisible hand that shapes human behavior (Clear 2018). A cuing environment can serve as a habit trigger for automatic behavior. It is important because it could prompt students to perform the behavior consistently and then to trigger the 


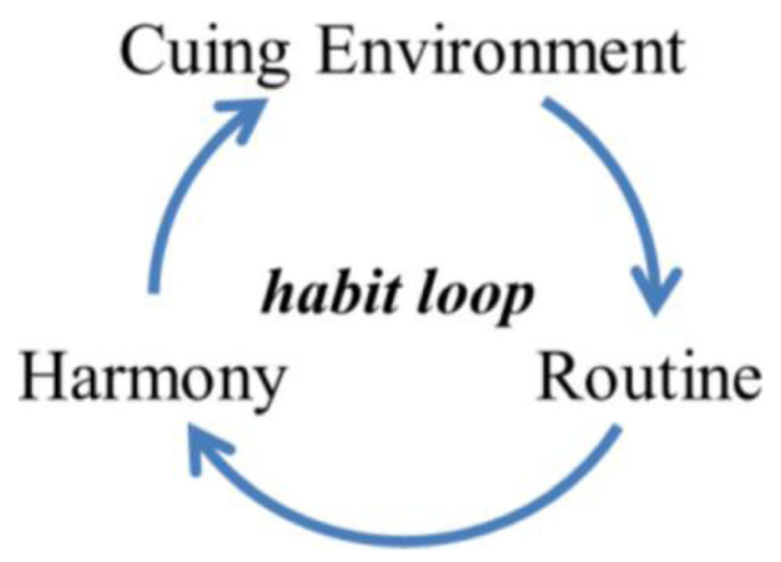

Fig. 1 The habit loop

learning behavior (Lally and Gardner 2013). Habits are formed when actions are tied to a trigger by consistent repetition. When a habit is triggered, people have an automatic urge to do the action; they sometimes do it without consciously knowing doing it. For example, brushing teeth is a habit. When most people wake up in the morning, they go to the bathroom and brush their teeth automatically, without asking themselves whether they want to do so in that morning. Occasionally, the action is so automatic that people may forget later in the day that they had brushed their teeth. An appropriate cue should be easy to identify by a learner and to influence habit formation, supporting the development of automaticity.

Psychologists have found that habits are cued by context (Wood and Neal 2007). Furthermore, there are two forms of contextual cues: direct cuing and motivated cuing. First, direct cuing refers to repeated association between routine and environment. Such a continuity may facilitate the encoding of learning patterns in students' procedural memory. For this reason, habits can be developed via providing a constant environment, for example, reading in the same room at the same time. Another example is writing a diary. Students tend to do the writing in the same notebook on the same table at a specific time. Second, motivated cuing refers to the rewarding experiences in the past. In other words, previous successful experiences may become a cached motive to do the same thing (Daw et al. 2005). For doing so, the cuing environment should include a supporting mechanism, for example, setting feasible plans before solving a complex learning task, like creation in STEM education contexts. On the other hand, some research also shows that a good everyday habit could be disrupted when specific contexts are changed (Wood et al. 2005).

\section{Routine}

The second component of the habit loop is the behavioral patterns we repeat most often, literally etched into our neural pathways. Through repetition and practice, it is possible to form (and maintain) new habits in which new response mechanisms are formed. A good way to start forming a new habit is to keep it easy and simple, as Lally et al. (2010) found that complex behaviors took longer time to become habits in everyday life. 
People's behaviors and actions can be goal directed or habitual. Goal-directed actions are rapidly acquired and regulated by their outcome. Habitual actions are reflexive, elicited by antecedent stimuli rather than their consequences. If people engage in goaldirected behaviors on a routine basis, it may become habitual. A habit may initially be triggered by a goal, but over time that goal becomes less necessary and the habit becomes more automatic. Performance of instrumental actions in rats is initially sensitive to post-conditioning changes in reward value, but after more extended training, a behavior comes to be controlled by stimulus-response (S-R) habits that are no longer goal-directed. It has been shown that it is possible to change a goal-directed behavior with a habitual behavior if people are engaged in certain behaviors repeatedly or on a routine basis (Aarts and Dijksterhuis 2000).

Some research has shown that the number of repetitions required to form a habit depends on the complexity of the task (Lally et al. 2010). For example, it will take 18 or fewer days for easy tasks (e.g., riding a bicycle, drinking more water) and up to 254 days for more complex tasks (e.g., going to the gym). Ericsson et al. (1993) argue that it takes as long as 10 years to develop a habit of very high-level performance of complex tasks. Moreover, van Merriënboer (1997) distinguishes recurrent tasks (e.g., those that are performed more or less the same way regardless of surrounding circumstances) from non-recurrent tasks (e.g., those that require modifications in performance depending on variations in the circumstances). Recurrent tasks are more amenable to the formation of automated responses and the development of habits, whereas non-recurrent tasks typically require the activation of mental models to perform some aspects of the task, and, as a result, are not so easily automated. The literature on habits of mind could be interpreted in part as referring to how a person develops coping mechanisms to respond to non-recurrent tasks.

Cognitive scientists often refer to schema and automaticity when discussing cognitive processes involved in habit formation (Anderson 1992; Schank and Abelson 1977). Since habit refers to a behavior that is done automatically with little thought, in investigating how learning habits are formed in various circumstances with different learners, Lally et al. (2010) explore on strategies to initiate a new behavior, support contextdependent repetition of this behavior (cuing environment), and facilitate the development of automaticity by repeating a behavior in a consistent setting in order to increases automaticity. In sum, habit formation is the process by which a new behavior, that is, routine, becomes automatic (Bargh 1994).

\section{Harmony}

The third component of the habit loop refers to the result of habit activation. Through routine behavior and action, people may feel that their needs get fulfilled and they receive inner rewards (Phillips et al. 2016; Wiedemann et al. 2014). Such rewards may facilitate people to continue their habit. In our habit loop, we address "harmony" as a psychological outcome of habit to pursue. Csíkszentmihályi (1991) describes harmony as "inner congruence" ultimately leading to inner strength and serenity. For being in harmony, Csíkszentmihályi (1991) suggested that one should first set up a challenging life goal, and then make efforts to resolve it. During the processes of resolving the life goal, one achieves a unified psychological experience. 
Harmony means peace, agreement, or concord. A cross-cultural psychological survey showed that people regarded a sense of inner harmony as their happiness (Fave et al. 2016). Psychologists have found that the most important factor of happiness is social and relational; furthermore, people value their relations with family, lovers, or friends, which in turn influence their inner peace (Saphire-Bernstein and Taylor 2013). For some people, they value their relations with society. Most people look forward to a peaceful and healthy environment. For building it, virtue education is required. As Aristotle said, "happiness is prosperity combined with virtue," and "the greatest virtues are those which are most useful to other persons," suggesting that to build a virtuous environment is to establish harmony.

In harmony, people may feel a sense of enjoyment, pleasure, fulfillment, satisfaction, achievement, and ultimately inner peace. Such feeling of harmony is usually coupled with their feeling of peacefulness about surrounding environment, composing people and objects they interact when they activate the routine behavior. As a consequence, this psychological experience in the new habit possibly increases a positive feedback that helps the repetition of the new behavior in the future (Lally and Gardner 2013; Neal et al. 2012). Because Rothman (2000) also noticed that "the feeling of satisfaction indicates that the initial decision to change the behavior was correct" (p. 66), the role of positive feelings is to reinforce cue-response associations.

When students always acquire the aforementioned positive feelings after the routine activity, their habit formed becomes a hobby. In other words, after a habit is formed, with repeated feelings of harmony as the outcomes of activating the habit, students would behave for interest-pursuing the routine activity whenever there is opportunity. By continuing a particular hobby for a long period, students can gain considerable knowledge and skills in that area of interest.

\section{Habit loop in IDC theory}

\section{Habit and interest}

Educational researchers and instructional designers investigated the relationship between interest and habit and how motivation promotes learning (i.e., result in more time spent on learning tasks) in the context of habit formation. For example, developing a reading habit is also developing interest in reading. Once students have the interest, they will concentrate and make sincere efforts. The notion of interest encapsulates much of what is called motivation and volition (Keller 2008). To cultivate an interestdriven creator, there is a need to (a) determine those habits that contribute to interestdriven creation, (b) identify current and desired habits of learners, (c) determine which learning habits of learners require additional support and development, and (d) develop an instructional design framework that fosters the habit of interest-driven creation.

Learning driven by interest with process mimicking in the creation process will produce no lasting effect on students unless it is repeated regularly in daily learning activities to accumulate its effects. To exert a long-term impact on student learning, a natural way is to cultivate creation with interest as a habit, desirably a lifelong habit.

Interest and habit can positively reinforce each other. There are two types of interest: situational interest and individual interest (Hidi and Renninger 2006). Situational interest refers to focused attention and the affective reaction triggered in the moment by 
environmental stimuli, but situational interest may or may not last over time. Note that situational interest is similar to triggering interest (arousing curiosity) in the interest loop (Wong et al. 2020). Individual interest denotes the enduring tendency to reengage a particular activity overtime with an expectation of positive feelings based on previous experience. Thus, individual interest represents internal drive to seek for opportunities to reengage the activity. Also, since individual interest is similar to hobby-an activity one does for pleasure when not working-it is desirable that most learning activities students find as pleasurable as their hobbies so that they can learn not under any academic pleasure.

To develop interest from situational interest to individual interest, building habit through scheduled routines in schools has come to play. Scheduled routines in schools provide students ample opportunities to participate the activity they have experience of situational interest before. The more opportunities provided for students to participate such an activity, the more likely they deepen their interest from situational interest to individual interest, and, in turn, the more likely they build a habit of this activity. Thus, interest development and habit formation reinforce each other.

\section{Habit and creation}

Students who value effort perceive ability as a malleable skill and have a growth mindset; in contrast, those who think intelligence is inherent and unchangeable exert less effort to succeed and have a fixed mindset (permanent capacity) (Hochanadel and Finamore 2015). Students' growth or fixed mindset was evidenced to influence their habit (Yan et al. 2014). For example, a student with growth mindset may be intrinsically motivated to learn and tend to have a habit of restudying.

Forming a habit of creation is not an easy task. Creation requires a growth mindset of the students (Dweck 2006). Creation includes complex cognitive behaviors. While we are more concerned with the development of complex cognitive behaviors than simple repeated behaviors, it is challenging to unpack the underlying mechanism of how a certain cognitive action becomes an automatic behavior, and is eventually sustained to become a habitual routine behavior in a long term. The formation and execution of habits involving complex cognitive behaviors is more than the simple chain of stimulus and response since one's habit is highly related to the influence of affective aspects and cognitive control. Fortunately, creation is composed of three components; building habit for each of the three components can be simpler and more effective than that of the fully fledged creation process (Ericsson et al. 1993).

The recent literature on technology adoption, for instance, has highlighted the role of habit, emotion, and environmental cues to explain the habitual continuing use of information technology (De Guinea and Markus 2009; Lee 2014). This view is dramatically different from the traditional theoretical view on the continued use of technology (e.g., technology acceptance model) that emphasizes the role of intentional and reasoned actions. De Guinea and Markus (2009) argue that the habitual use of information communication technology is less driven by intentional actions but is more driven by triggers in environmental cues.

Likewise, for interest-driven creation activities, it may start as the intentional and reasoned activities for students; it could become a habitual routine behavior in a long 
term. The role of environmental cues is important in this process. Environmental cues are habit triggers, or signals to the brain to prepare for an automatic mode, whereby a habit forms when a behavior is initiated in a consistent cuing environment (Lally and Gardner 2013). In other words, the arrangement of environmental cues in creation activities may facilitate students to become self-directed learners by promoting sustainable learning and instilling the habits of creation. Students periodically engage in interest-driven creation tasks with the various loops iterated and repeated.

Interest-driven creation can be triggered by environmental cues in various creation sub-activities (initiating, combining, and staging). For example, imitating is concerned with taking in plentiful existing knowledge and is the preparation process of creation (Chan et al. 2019). The simplest way of acquiring knowledge is through a change of response to a single stimulus after repeated exposure to that stimulus. For example, when we are listening to other people, we are mirroring the speakers with our tongues as if we are simulating their speech by speaking the same speech ourselves (Fadiga et al. 2002). When combining, all concepts and knowledge created are combinations of existing concepts and knowledge, and all artifacts created are actually combinations of features of existing artifacts.

The creation activities that students repeat often form a routine, just as the daily routine governed by the school timetable. Imitating, combining, and staging, the three components of the creation loop, can repeatedly happen in the process of interestdriven creation, forming a habitual routine behavior. Harmony refers to the outcomes of habits of interest-driven creation. Through routine, students engage with interest; through harmony, they gain the awareness that their energy has been well invested and that their needs are fulfilled, they feel a sense of satisfaction, and they feel at peace with their surroundings and the world (Fig. 2).

\section{Operationalizing the habit loop in school settings}

Based on the aforementioned explanation of the habit loop, we attempt to provide a clearer understanding of how to nurture and reinforce learning related habits by operationalizing the habit concept within the context of the school environment through the following four steps:

\section{Start from manageable creation behaviors}

To nurture learning habits in IDC, students need to have a good start. Educators need to get students at a manageable pace. Students will be overwhelmed if they are to form too many new habits within a short period of time. Success is more likely to occur when students are focusing on only one or two changes, which is manageable for them at a time. Reaching the levels of automaticity is more difficult for complex behaviors as compared with that of simpler ones (Verplanken and Wood 2006) given that the former involves more thinking processes (Wood et al. 2002). For this reason, when developing students' habits, it is easier for them to start with creation activities which are not too complex. We can take a spiral progressive approach to get students engaged in more complex creation activities at a later stage. 


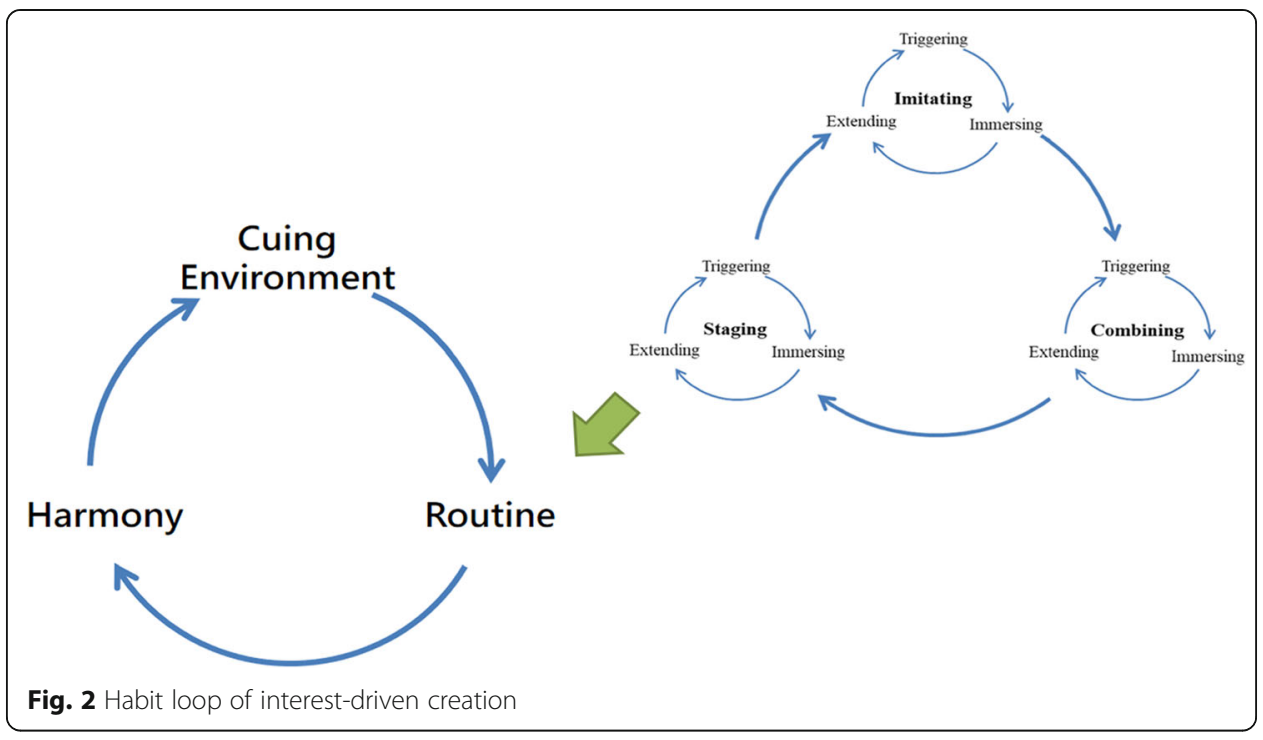

\section{Create a cuing environment (a reminder)}

If students start to engage in creation work at a specific time for a fixed length of period, we should provide a cuing environment which makes them not to hesitate from the beginning. It is effective to remind students at the beginning of habit formation by clarifying the goal of the learning activities with the students. If the student knows the purpose of the activity, he/she can focus on the learning, and the study will be goal-directed which can become habitual later. For example, one intervention of designing IDC-based learning activity was called Modeled Sustained Silent Reading (MSSR) (Chan et al. 2018; Wong et al. 2020). MSSR was aimed to help students to form reading habit. In MSSR, students repeatedly exposed to "modeled" and "silent" environment. The element of "modeled" and "silent" serve as context cues of the reading behaviors.

Another cue could be the educator himself/herself. Teachers can be the role model of students as an interest-driven creator. Previous research on mirror neurons show that observing other people's behaviors may facilitate unintentional and non-conscious mimic behaviors (Rizzolatti et al. 1996). The finding suggests that students should be situated in a learning environment with good behaviors. In classrooms, teachers should become the role models so that students can mimic routines that we want them to do. Besides, the teachers should also set up a norm that is conducive to develop crowd habits in classrooms. As MSSR, to help students form reading habit, their teacher also read on a routine basis for long period of time (Chan et al. 2018; Wong et al. 2020).

It is helpful to view the process of habit development, especially for more complex forms, as the interplay between one's agency and situational resources. That is, one's will alone is not sufficient to develop and sustain routine behaviors in a long term, unless situational opportunities and resources are provided as affective and cognitive support. Situational resources act as triggers in a cuing environment. For instance, the design of an immersive simulation in classrooms (Lui and Slotta 2014) demonstrates the possibility of using technology as a trigger for collaborative inquiry activities. The large public display on the classroom walls provides a situational cue where students can easily monitor the collection of ideas and the current status of the community knowledge. When entering the room with the situation cue, the students are engaged 
in actions where they can easily check and monitor ideas. Further, the immersive simulation on the large display may be able to trigger routine behaviors for students to check what questions are posted and to contribute ideas for collective knowledge advancement.

When we shift our focus of habit formation from the inside of one's mental activity to the interplay between individuals and environmental cues, designing and embedding triggers in environments become a central issue. The criticality of environmental cues in habit development suggests the need to design tools and platforms that effectively provide relevant triggers. With that, we can explore how the recent development of emerging technologies can help provide effective and meaningful triggers to students. For instance, the recent use of wearable technologies has demonstrated the potential of detecting, capturing, and analyzing data generated by individuals with a wearable device. Data is seamlessly collected in an unconscious manner, hence reducing one's cognitive load of tracking and monitoring. Data from such wearable devices can prompt individuals to evaluate their performance and in some cases can provide motivational triggers to alter certain habitual behaviors. Such applications for raising self-evaluation and self-regulation have been proposed mainly in the field of healthcare systems, including the visualization of eating habits and the sensor-based system to monitor dietary habits (Faudot et al. 2010; Shuzo et al. 2010).

However, the application of such wearable and data-based technologies for educational purposes is still in its infancy. Perhaps, learning analytics is the most actively researched area that concerns with the use of the vast amount of data for enhancing teaching and learning (Siemens 2013). Considering that many online crowd-based learning platforms leave a vast amount of learner's habitual data such as reading, writing, and study patterns, such data can be automatically detected and made meaningful to users as motivational triggers to reinforce positive habits or to develop new habits.

Get students engaged in the behavior on a routine basis (do the same thing at the same time every day or on a regular basis)

It is essential for students to practice the new habit regularly until it becomes a routine in their life. Postponement or interruption should be avoided because it weakens the habit formation. The routine schedules in schools provide such a possibility as educators can get students engage in knowledge creation work in a fixed time slot. For example, in MSSR, when students go to the classroom in the early morning of every day, the same silent classroom, same time, and the teacher and other classmates who are reading books form the cuing environment for forming the reading habit. The students have been reading on a routine basis for long period of time.

The Fostering a Community of Learners (FCL) (Brown 1992) is a classic example of classroom implementation where students were able to develop a habit of sharing their ideas and interest horizontally in a classroom and also vertically across different grades (Collins et al. 2004). FCL employed a dramatically different structure where students are engaged in crosstalk and reciprocal teaching to discuss across different topics, to work in different groups, and to co-teach each other for understanding. Such built-in activities and structures influenced the emergence of a classroom culture where students were able to freely share ideas and ask questions. This culture is a huge deviation 
from the traditional classroom culture where individual students often engage in fixed activities. What makes FCL successful is the fact that the routine activities of sharing and discussing ideas function not as simply procedural activities, but were operated as a system with the interdependent activities that the underlying objectives are articulated (Bielaczyc and Collins 1999). That is, both teachers and students as community members were aware of why they are engaged in certain procedures, thereby creating the shared understanding about their actions.

There has been increasing evidence that the automaticity of habitual behaviors is not the simple repeated coupling of stimulus and response, but the complex interaction between internal and external forces (Lee 2014). Most of existing technology-integrated interventions and applications tend to target health or life-style related behaviors such as brushing teeth, changing food consumptions, and weight loss. Successful interventions specifically targeting learning habits are scarce. Unlike more reflexive motor habits, learning-related habits are to some extent driven by goal-directed automatic behaviors. Hence, the process from its formation to automation is governed by the interaction of multiple factors including emotion, motivation, intention, social pressure, and environmental configurations. This fact implies that simply changing a part of one's routine is unlikely to be successful if the external situations and social influences remain unchanged.

Indeed, learning-related habits are not easy to form or change. The existing research on learning volition may provide insights into unpacking the complex process of habit changes. Learning volition research suggests that even highly-motivated students often lose their motivation for learning due to the lack of volition. In general, the volition control for a goal pursuit follows three stages, namely goal-setting, goal striving, and goal attainment (Kim and Bennekin 2013). Here, motivational factors play critical roles in the initial stage of goal setting, while volition is critical for goal striving. The volition theory implies that simply presenting routine feedback for self-monitoring via digital solutions alone does not necessary guarantee the formation of good habits or the cessation of undesirable habits. However, it appears that the design of some digitalized selfmonitoring applications aiming to affect habitual behaviors is based on the naive assumption that simply providing users with routine feedback is likely to increase their self-awareness on habitual behaviors. On the contrary, some digitalized feedback solutions (e.g., emails, SMS messages) are easy to ignore and be forgettable; hence, it is unlikely to create sustainable habit changes.

However, digital solutions to change habitual behaviors in daily routines necessitate the in-depth understanding about the nature of rituals and norms in schools and home, where routines are operated in rather different ways. First, schools as social institutions have several types of rituals to reward or inhibit certain behaviors. Bernstein (1975) in his classic work on institutionalizing codes, class hierarchy and membership suggests that schools have "differentiating rituals" to reward students who conform to school norms and values (e.g., award ceremony), and "integrating rituals" to show a collective identification with the school (e.g., pep rallies, sports events). Embedding technologyintegrated solutions that fit well into such existing rituals in schools is likely to be more successful than those that require disruptions and alterations in existing rituals. The school-based intervention research by Poole et al. (2011) also supports the importance of congruency between habit changing attempts and school rituals in that one of the 
success factors of school-based interventions is to support teachers in making space for digital solutions to be used in typical school days and routines.

Next, routines at home operate differently in that they are heavily influenced by the cultural beliefs and practices of parents. The cultural comparison study on preschool children's home routines reveals that the Asian children spent more time on pre-academic activities and visiting the library than the Euro-American students, who spent more time on household chores and reading at bedtime (Parmar et al. 2004). Such different patterns of daily activities may be an indication of different norms and values of Asian parents. While it is challenging to change such epistemic and cultural beliefs, one potentially promising solution to change routines at home is to utilize everyday objects as a catalyst to disrupt or change behaviors. Interventions that require a great deal of adoption and changes at the initial change is unlikely successful. Everyday objects (e.g., cups) already embedded in daily routines can function as an effective catalyst for affecting habitual behaviors (Kao and Schmandt 2014). Eventually, learning habits can be formed, strengthened, and sustained through the close linking of routines between home and school, through the constant availability of support systems whether they are mediated by human, technology, or both. Hence, parental involvement in the habit loop is essential, especially in early years of student development. For example, in an intervention called robotics program in one Singapore Primary school, besides of routine activities in school, students also made robots at home during school holiday time for sustaining their habit.

\section{Reinforce students' satisfaction}

The sense of satisfaction can help students engage in new behaviors in the habit loop. If students are satisfied by the experience of a new routine, they typically attempt to facilitate behavioral changes, and vice versa. Specifically, we consider that the satisfaction of the habit loop will increase the strength of the habit formation, whereas low satisfaction will gradually weaken it. Satisfaction may be boosted by reinforcing un-existing wanted habits, or disrupting existing unwanted habits. Regarding the former, the satisfaction of habit loop can potentially help students form new good habits, such as inculcating the reading habit (Asraf and Ahmad 2003) or becoming an amateur astronomy (Azevedo 2013); regarding the latter, satisfaction can also help students break old "notso-good" habits, such as weight loss (Finch et al. 2005) and smoking cessation (Baldwin et al. 2006). That is, the satisfaction of habit loop can apply a habit formation approach in designing behavior change interventions.

The key to students' satisfaction is to create successful learning experience as often as possible. Fortunately, educators and researchers have already provided several feasible ways of doing so. Generally speaking, successful learning experience can be achieved by cognitive and affective scaffolding. Cognitive scaffolding may support students to complete difficult learning tasks, such as questioning, providing hints, explaining, coaching, positive feedback, and modeling (see van de Pol et al. 2010), while affective scaffolding may encourage students to finish tasks and prevent possible negative emotions, such as anonymity (Cornelius et al. 2011) or information hiding (Cheng et al. 2009). In particular, teachers should provide low-ability students with additional assistance, so that students can acquire the satisfaction in the habit loop of interest- 
driven creation. For example, in MSSR, each time after reading, students learned something new, and, as a result, they had a sense of achievement and satisfaction. As time goes on, reading becomes the hobby for some students MSSR (Chan et al. 2018; Wong et al. 2020).

Building good habit is important and fundamental for education, be it in school or out of school. It will have in-depth impact on student's lifelong learning and will nurture them as an interest-driven creator. There are so many intervention projects in schools which use innovations to transform students learning experiences. However, many of these interventions' impact on school practices are limited. More research is needed in addressing the fundamental issues on education. Nurturing good habit is one of them.

\section{Case studies}

In this section, we examine the details of its habit loop design. One typical example of designing IDC-based learning activity is MSSR (Chan et al. 2018; Wong et al. 2020). MSSR instills the habit of reading in students with the hope that they will ultimately become lifelong readers. In MSSR, the cuing environment was silent classroom; the routine was that students and the teacher read in the early morning; and the harmony was that students' positive psychological feelings after reading-the routine of the established habit.

Individual teachers in Taiwan observed that when they practice MSSR, their students were more calm in their behavior than before. One elementary school principal reported that their students were less worried in campus after practicing MSSR. ${ }^{1}$ Perhaps, this indicates that habit of interest-driven reading enables students to be more harmonious with their social and physical environments around.

From the perspective of interest, if a student who has no reading experience before finds a book with surprising information or character identification that draws the student attention to read, we can say that the student's situational interest is sparked by this first experience. This interest may or may not last over time. However, being a scheduled routine in school, MSSR provides opportunities for students to develop their reading interest progressively from situational interest to individual interest (or hobby), and the student values the opportunity to reengage the reading experience again and opt to pursue such opportunity. Such interest development, in turn, will speed up the formation of reading habit.

From the perspective of creation, a reading habit is the foundation for acquiring knowledge in the world. This is also the preparing process of creating new knowledge because creation needs to combine features of existing models, knowledge, and concepts. Thus, every lifelong learner must be a lifelong reader. Incubating the habit of reading should start early in schools.

Another example is the Singapore Primary school's robotics program mentioned before. A group of selected students participates in the program every Monday afternoon in a special classroom with various robotic parts. The students signed up for the

${ }^{1}$ Individual school teachers who took the MSSR training course mentioned their observations of the change of their student behavior after practicing MSSR in 2013. In the same course, as an invited speaker, Principal L. L. Chen of Reimei Elementary School presented with statistical result the obvious drop of number of cases that students got wounded in campus after practicing MSSR. 
activities based on their interest. Every Monday afternoon during school term, guided by the same group of teachers, the students engage in making (programming, building) robots. Over time, they form the habit of creating robots. As a consequence, they even make robots at home. The same time, venue, and teachers serve as the cuing environment for triggering their making behaviors. The students make robots on a routine basis and enjoy the making activities very much. After the making activities, the students have a great sense of achievement once their robots can move and compete with other robots.

In summary, habits of interest-driven creation are automatic behaviors, which respond to environmental cues, develop through repetition of creation behavior in consistent contexts, and reinforce a learner's harmony. In short, to create a habit, a learner needs to repeat the behavior in the same situation. Hence, we can adopt that the habit loop may provide a mechanism for establishing new behaviors, and learning habit formation is a desired outcome for many interventions.

\section{Issues in habit formation and future research}

Can habit formation be cultivated by educators? Obviously, the answer is yes. As discussed earlier, the mental processes and dispositions for habit can be taught and practiced, so that they become habitual ways of working towards thoughtful, purposeful, self-regulated actions in facing the challenges of life. Having said this, there are many issues that remain to be addressed when cultivating students' habit in interest-driven creation.

The first issue is time. The widely touted theory, highlighted in a 1993 psychology paper and popularized by Malcolm Gladwell's book Outliers (Gladwell 2008), says that anyone can master a skill with $10,000 \mathrm{~h}$ of practice. One can say that habit formation is the basis for becoming an expert in a particular area. If we are able to get students accumulate considerable amount of time on a regular basis if not daily, students are more likely to form a habit and become an expert in the area later. However, it is not realistic to expect students to be an expert in too many areas because forming habits takes time, but students' time is not unlimitedly as they need to do other activities as well. Therefore, educators and researchers need to prioritize the learning habits we would like students to form. Do we need to take step-by-step approaches to address more fundamental learning habit (e.g., reading) first? If yes, what are those more fundamental and important learning habits that we want students to form so that they can be successful in learning?

The second issue is the satisfaction (reward) achieved out of the new learning practices. As many learning habit we would like the students to form may not have an immediate impact on students' learning measured by traditional exams, how do we make students more satisfied through the new learning experiences? More research is needed in this area to reinforce the students' satisfaction from the new learning experiences.

The third issue is the relationship between interest and habit in IDC theory. We need to tap on students' interest in cultivating their learning habit. If we provide a cuing environment for students' habit formation, is this in alignment with their interest? What if students do not have this interest at the beginning? Or can they develop interest after we introduce them the new learning practices? 
The fourth issue is the balance of educator's effort and students' effort in habit formation. The intrinsic motivation is important for habit formation. Educators and parents can provide cuing environments and provide scaffolds and support. How much scaffold and support are needed? How to increase students' intrinsic motivation for the habit formation?

Last but not least, for cultivating students' interest-driven creation habits, do educators, parents, or researchers, as students' learning designers, need to form habit in interest-driven creation or design learning environments for cultivating and developing interest-driven creators? If yes how?

We may not have immediate answers for all these questions and there could be more issues to be addressed. More research and discussions are needed in exploring these under-explored areas. We raise the questions here to stimulate more in-depth discussions among educators, parents, researchers, and policy makers.

\section{Conclusion}

This paper is the continuation of two earlier papers in this thematic series that focused on two anchored concepts of IDC theory-interest and creation. To recap, in the first anchored concept, interest, we talked about how to put interest as the first design consideration. That is, students must learn with interest or learning is interest-driven (Wong et al. 2020). Since the concept interest comprised three components-curiosity, flow, and meaningfulness - this means that students must learn curiously, immersively, or meaningfully. Learning with interest is important because students will spend more time and energy and enjoy it. In the second anchored concept, creation, we talked about how we treat a learning activity as a creation activity of knowledge or skills (Chan et al. 2019). Thus, an interest-driven learning activity is also regarded as an interest-driven creation activity. Since the concept creation comprised three components-imitating, combining, and staging - thus, an interest-driven creation activity also comprised interest-driven imitation, interest-driven combination, and interest-driven staging.

In the third and final anchored concept, habit, as discussed in this paper, we posit that if students learn with interest habitually (as when following a school timetable that regulates daily routines), and their learning process emulates the creation process, then students will become creators, hopefully, lifelong interest-driven creators (Chan et al. 2018). Since the creation process is composed of imitating, combining, and staging sub-processes, when talking about nurturing students' habits of interest-driven creation, we are also talking about nurturing habits of interest-driven imitating, interest-driven combining, and interest-driven staging. It is important to note that when habit of interest-driven creation is formed, creation per se then becomes students' individual interest of hobby. The students also then become self-pursuit creators. Furthermore, repeating such interest-driven creation in daily routines, students experience harmony: positive feelings such as fulfillment, satisfaction, achievement, and inner peace.

To conclude, we hope that IDC theory will serve its purpose well by providing a valid basis for studying and understanding the cultivation of interest in learning, creation, and problem solving complex tasks and development of habitual interest-driven creators. We, as researchers ourselves, will endeavor to continue using this theory to guide our research to resolve the ongoing tensions between academic performance and 
interest in learning among Asian schools. We extend our invitation to all scholars across various disciplines and countries to help us in this endeavor to find ways that can lead to better future learning.

\section{Acknowledgements}

Not applicable.

\section{Authors' contributions}

WC was the main author of the paper who conducted literature review, derived the key framework, and wrote the majority part of the paper. WC is the corresponding author of this paper. TWC was the proposer of the IDC theory and wrote the case study on MSSR in the paper. LHW and CKL were the anchor authors of the interest loop paper and the overall research agenda paper of IDC respectively, which, together with this manuscript and the creation loop paper spearheaded by TWC, constitute the series of IDC papers with intertwining concepts. We are making references to the concepts presented in each other's paper. CL and HC were the early co-developers of the habit loop process which provided the skeleton of the framework that WC developed, and were involved in tightening up the final version of this paper. SLW, JM, HJS, SM, and XG offered crucial ideas for us in developing paper and assisted us in refining the paper. ZP did revisions on the manuscript based on the reviewers' comments. The authors read and approved the final manuscript.

\section{Funding}

Not applicable. This is not a funded research project.

\section{Availability of data and materials}

Not applicable. This is a conceptual paper without empirical data collected.

\section{Competing interests}

The authors declare that they have no competing interests.

\section{Author details}

${ }^{1}$ National Institute of Education, Nanyang Technological University, Singapore, Singapore. ${ }^{2}$ National Central University, Taoyuan, Taiwan. ${ }^{3}$ National Taipei University of Nursing and Health Sciences, Taipei, Taiwan. ${ }^{4}$ Central China Normal University, Wuhan, China. ${ }^{5}$ Universiti Putra Malaysia, Seri Kembangan, Malaysia. ${ }^{6}$ Charles Darwin University, Casuarina, Australia. ${ }^{7}$ Ewha Womans University, Seoul, South Korea. ${ }^{8}$ Indian Institute of Technology Bombay, Mumbai, India. ${ }^{9}$ East China Normal University, Shanghai, China.

Received: 28 August 2019 Accepted: 18 February 2020

Published online: 14 May 2020

\section{References}

Aarts, H. A. G., \& Dijksterhuis, A. J. (2000). Habits as knowledge structures: Automaticity in goal-directed behavior. Journal of Personality and Social Psychology, 78, 53-63.

Anderson, J. R. (1992). Automaticity and the ACT theory. American Journal of Psychology, 105, 165-180.

Andrews, B. R. (1903). Habit. The American Journal of Psychology, 14(2), 121-149.

Asraf, R. M., \& Ahmad, I. S. (2003). Promoting English language development and the reading habit among students in rural schools through the guided extensive reading program. Reading in a Foreign Language, 15(2), 83-102.

Azevedo, F. S. (2013). The tailored practice of hobbies and its implication for the design of interest-driven learning environments. Journal of the Learning Sciences, 22(3), 462-510.

Azikiwe, U. (1998). Study approaches of university students. WCCI Region II Forum, 2, 106-114.

Baldwin, A. S., Rothman, A. J., Hertel, A. W., Linde, J. A., Jeffery, R. W., Finch, E. A., \& Lando, H. A. (2006). Specifying the determinants of the initiation and maintenance of behavior change: An examination of self-efficacy, satisfaction, and smoking cessation. Health Psychology, 25, 626-634.

Bargh, J. A. (1994). The four horsemen of automaticity: Awareness, intention, efficiency, and control in social cognition. In R. S. Wyer \& T. K. Srull (Eds.), Handbook of social cognition: Vol 1 basic processes (pp. 1-40). Hove: Lawrence Erlbaun Associates Publishers.

Bernstein, B. (1975). Class, codes and control: Towards a theory of educational transmissions (Vol. III). London: Routledge \& Kegan.

Bielaczyc, K., \& Collins, A. (1999). Learning communities in classrooms: A reconceptualization of educational practice. Instructional-Design Theories and Models: A New Paradigm of Instructional Theory, 2, 269-292.

Brown, A. L. (1992). Design experiments: Theoretical and methodological challenges in creating complex interventions in classroom settings. The Journal of the Learning Sciences, 2(2), 141-178.

Chan, T. W. (2013). L4C: Core competencies of twenty-first century and transforming schools through e-learning. Global Chinese Journal of Computers in Education, 9(1-2), 169-183.

Chan, T.-W., Looi, C.-K., Chang, B., Chen, W., Wong, L.-H., Wong, S. L., et al. (2019). IDC theory: creation and the creation loop. Research and Practice in Technology Enhanced Learning, 14(1), 1-29.

Chan, T.-W., Looi, C.-K., Chen, W., Wong, L.-H., Chang, B., Liao, C. C. Y., et al. (2018). Interest-driven creator theory: Towards a theory of learning design for Asia in the twenty-first century. Journal of Computers in Education. https://doi.org/10.1007/s40692-018-0122-0 Published online.

Cheng, H. N. H., Wu, W. M. C., Liao, C. C. Y., \& Chan, T. W. (2009). Equal opportunity tactic: Redesigning and applying competition games in classrooms. Computers \& Education, 53(3), 866-876.

Clear, J. (2018). Atomic habits: An easy \& proven way to build good habits \& break bad ones. New York: Penguin Random House. 
Collins, A., Joseph, D., \& Bielaczyc, K. (2004). Design research: Theoretical and methodological issues. The Journal of the Learning Sciences, 13(1), 15-42.

Cornelius, S., Gordon, C., \& Harris, M. (2011). Role engagement and anonymity in synchronous online role play. The International Review of Research in Open and Distributed Learning, 12(5), 57-73.

Costa, A. L., \& Kallick, B. (Eds.). (2008). Learning \& leading with habits of mind: 16 essential characteristics for success. Alexandria: Association of Supervision and Curriculum Development Retrieved September 172015 from www.asdc.org.

Csíkszentmihályi, M. (1991). Flow: The psychology of optimal experience. New York: Harper Perennial.

Daw, N. D., Niv, Y., \& Dayan, P. (2005). Uncertainty based competition between prefrontal and dorsolateral striatal systems for behavioral control. Nature Neuroscience, 8, 1704-1711.

De Guinea, A. O., \& Markus, M. L. (2009). Why break the habit of a lifetime? Rethinking the roles of intention, habit, and emotion in continuing information technology use. MIS Quarterly, 33(3), 433-444.

Durhigg, C. (2012). The Power of Habit: Why We Do What We Do in Life and Business. New York: Random House.

Dweck, C. S. (2006). Mindset: The new psychology of success. New York: Random House.

Ebele, U. F., \& Olofu, P. A. (2017). Study habit and its impact on secondary school students' academic performance in biology in the Federal Capital Territory, Abuja. Educational Research \& Reviews, 12(10), 583-588.

Ericsson, K. A., Krampe, R. T., \& Tesch-Römer, C. (1993). The role of deliberate practice in the acquisition of expert performance. Psychological Review, 100(3), 363-406.

Fadiga, L., Craighero, L., Buccino, G., \& Rizzolatti, G. (2002). Speech listening specifically modulates the excitability of tongue muscles: a TMS study. European Journal of Neuroscience, 15(2), 399-402.

Faudot, T., Lopez, G., \& Yamada, I. (2010). Information system for mapping wearable sensors into healthcare services: Application to dietary habits monitoring. In Proc. 2nd Int. Workshop on Web Intelligence and Virtual Enterprises (pp. 1-9).

Fave, A. D., Brdar, I., Wissing, M. P., Araujo, U., Solano, A. C., Freire, T., et al. (2016). Lay definitions of happiness across nations: The primacy of inner harmony and relational connectedness. Frontiers in Psychology, 7, 30.

Finch, E. A., Linde, J. A., Jeffery, R. W., Rothman, A. J., King, C. M., \& Levy, R. L. (2005). The effects of outcome expectations and satisfaction on weight loss and maintenance: Correlational and experimental analyses-a randomized trial. Health Psychology, 24, 608-616.

Gersick, C. J. G., \& Hackman, J. R. (1990). Habitual routines in task-performing groups. Organizational Behavior and Human Decision Processes, 47(1), 65-97.

Gladwell, M. (2008). Outliers. The stories of success. New York: Little, Brown and Company.

Griffin, P., McGaw, B., \& Care, E. (2012). The changing role of education and schools. In P. Griffin, B. McGaw, \& E. Care (Eds.), Assessment and teaching of 21st century skills (pp. 1-16). Dordrecht: Springer Science+Business Media B.V.

Hertel, P. T., \& Brozovich, F. (2010). Cognitive habits and memory distortions in anxiety and depression. Current Directions in Psychological Science, 19(3), 155-160.

Hidi, S., \& Renninger, K. A. (2006). The four-phase model of interest development. Educational Psychologist, 41(2), 111-127.

Hochanadel, A., \& Finamore, D. (2015). Fixed and growth mindset in education and how grit helps students persist in the face of adversity. Journal of International Education Research, 11(1), 47-50.

James, W. (1890). The principles of psychology. New York: Henry Holt and Company.

Jonassen, D. H., \& Grabowski, B. L. (1993). Handbook of individual differences. Learning \& Instruction. Hillsdale: Lawrence Erlbaum Associates.

Kao, H. L. C., \& Schmandt, C. (2014). MugShots: Everyday objects as social catalysts. In Proceedings of the 2014 ACM International Joint Conference on Pervasive and Ubiquitous Computing: Adjunct Publication (pp. 75-78) ACM.

Keller, J. M. (2008). An integrative theory of motivation, volition, and performance. Technology, Instruction, Cognition, and Learning, 6, 79-104.

Kim, C., \& Bennekin, K. N. (2013). Design and implementation of volitional control support in mathematics courses. Educational Technology Research and Development, 61(5), 793-817.

Lally, P., \& Gardner, B. (2013). Promoting habit formation. Health Psychology Review, 7(1), S137-S158.

Lally, P., van Jaarsveld, C. H. M., Potts, H. W. W., \& Wardle, J. (2010). How are habits formed: Modelling habit formation in the real world. European Journal of Social Psychology, 40(6), 998-1009.

Lee, W. K. (2014). The temporal relationships among habit, intention and IS uses. Computers in Human Behavior, 32, 54-60.

Lui, M., \& Slotta, J. D. (2014). Immersive simulations for smart classrooms: Exploring evolutionary concepts in secondary science. Technology, Pedagogy and Education, 23(1), 57-80.

Neal, D. T., Wood, W., Labrecque, J. S., \& Lally, P. (2012). How do habits guide behavior? Perceived and actual triggers of habits in daily life. Journal of Experimental Social Psychology, 48(2), 492-498.

Oxford Dictionary (2014). Habit. Retrieved January 1, 2018, https://en.oxforddictionaries.com/definition/habit

Parmar, P., Harkness, S., \& Super, C. (2004). Asian and Euro-American parents' ethnotheories of play and learning: Effects on preschool children's home routines and school behaviour. International Journal of Behavioral Development, 28(2), 97-104.

Peterson, G. R., Van Slyke, J. A., Spezio, M. L., \& Reimer, K. S. (2017). Habits in mind: Integrating theology, philosophy, and the cognitive science of virtue, emotion, and character formation. Boston: Brill.

Phillips, L. A., Chamberland, P.-É., Hekler, E. B., Abrams, J., \& Eisenberg, M. H. (2016). Intrinsic rewards predict exercise via behavioral intentions for initiators but via habit strength for maintainers. Sport, Exercise, and Performance Psychology, 5(4), 352-364.

Poole, E. S., Miller, A. D., Xu, Y., Eiriksdottir, E., Catrambone, R., \& Mynatt, E. D. (2011). The place for ubiquitous computing in schools: Lessons learned from a school-based intervention for youth physical activity. In Proceedings of the 13th international conference on Ubiquitous computing (pp. 395-404). Beijing: ACM press.

Raisbeck, L. D., Regal, A., Diekfuss, J. A., Rhea, C. K., \& Ward, P. (2015). Influence of practice schedules and attention on skill development and retention. Human Movement Science, 43, 100-106.

Rizzolatti, G., Fadiga, L., Gallese, V., \& Fogassi, L. (1996). Premotor cortex and the recognition of motor actions. Cognitive Brain Research, 3, 131-141.

Ronis, D. L., Yates, J. E., \& Kirscht, J. P. (1989). Attitudes, decisions, and habits as determinants of repeated behavior. In A. R. Pratkanis, S. J. Breckler, \& A. G. Greenwald (Eds.), Attitude structure and function (pp. 213-239). Hillsdale: Erlbaum.

Rothman, A. J. (2000). Toward a theory-based analysis of behavioral maintenance. Health Psychology, 19(1), 64-69. 
Rueda-Orozco, P. E., \& Robbe, D. (2015). The striatum multiplexes contextual and kinematic information to constrain motor habits execution. Nature Neuroscience, 18, 453-460.

Saphire-Bernstein, S., \& Taylor, S. E. (2013). Close relationships and happiness. In I. Boniwell, S. A. David, \& A. C. Ayers (Eds.), Oxford handbook of happiness. Oxford: Oxford University Press.

Schank, R. C., \& Abelson, R. P. (1977). Scripts, plans, goals and understanding. Hillsdale: Erlbaum.

Shuzo, M., Komori, S., Takashima, T., Lopez, G., Tatsuta, S., Yanagimoto, S., et al. (2010). Wearable eating habit sensing system using internal body sound. Journal of Advanced Mechanical Design, Systems, and Manufacturing, 4(1), 158-166.

Siemens, G. (2013). Learning analytics: The emergence of a discipline. American Behavioral Scientist, 57(10), 1380-1400.

van de Pol, J., Volman, M., \& Beishuizen, J. (2010). Scaffolding in teacher-student interaction: A decade of research. Educational Psychology Review, 22(3), 271-296.

van Merriënboer, J. J. G. (1997). Training complex cognitive skills: A four-component instructional design model for technical training. Englewood Cliffs: Educational Technology Publications.

Verplanken, B., \& Wood, W. (2006). Interventions to break and create consumer habits. Journal of Public Policy \& Marketing, 25, 90-103.

Whitebread, D. \& Bingham, S. (2013). Habit Formation and Learning in Young Children. Retrieved September 172015 from https://53b86a9de6dd4673612f-c36ff983a9cc042683f46b699207946d.ssl.cf3.rackcdn.com/the-money-advice-service-habitformation-and-learning-in-young-children-may2013.pdf

Wiedemann, A. U., Gardner, B., Knoll, N., \& Burkert, S. (2014). Intrinsic rewards, fruit and vegetable consumption, and habit strength: A three-wave study testing the associative-cybernetic model. Applied Psychology, 6(1), 119-134.

Wong, L.-H., Chan, T.-W., Chen, W., Looi, C.-K., Chen, Z.-H., Liao, C. C. Y., et al. (2020). IDC theory: interest and the interest loop. Research and Practice in Technology Enhanced Learning, 15(3).

Wood, W., \& Neal, D. T. (2007). A new look at habits and the habit-goal Interface. Psychological Review, 114(4), 843-863.

Wood, W., Quinn, J. M., \& Kashy, D. (2002). Habits in everyday life: Thought, emotion, and action. Journal of Personality and Social Psychology, 83, 1281-1297.

Wood, W., Tam, L., \& Guerrero Witt, M. (2005). Changing circumstances, disrupting habits. Journal of Personality and Social Psychology, 88, 918-933.

Yan, V. X., Thai, K.P., \& Bjork, R. A. (2014). Habits and beliefs that guide self-regulated learning: Do they vary with mindset? Journal of Applied Research in Memory and Cognition, 3(3), 140-152.

\section{Publisher's Note}

Springer Nature remains neutral with regard to jurisdictional claims in published maps and institutional affiliations.

\section{Submit your manuscript to a SpringerOpen ${ }^{\circ}$ journal and benefit from:}

- Convenient online submission

- Rigorous peer review

- Open access: articles freely available online

- High visibility within the field

- Retaining the copyright to your article

Submit your next manuscript at $\boldsymbol{\nabla}$ springeropen.com 